\title{
Comment on "The effect of maternal obesity on the success of labor induction with a cervical ripening double-balloon catheter and on pain perception during catheter insertion"
}

\author{
(1) Elif Nur Sevinç, (1) Kazım Emre Karaşahin
}

University of Health Sciences Turkey, Gülhane Faculty of Medicine, Department of Obstetrics and Gynecology, Ankara, Turkey

Date submitted:

28.04.2020

Date accepted:

26.06.2020

Online publication date:

15.12.2020

\section{Corresponding Author:}

Kazım Emre Karaşahin MD, University of Health Sciences

Turkey, Gülhane Faculty of Medicine, Department of Obstetrics and Gynecology,

Ankara, Turkey

emre.karasahin@sbu.edu.tr

ORCID:

orcid.org/0000-0002-4624-4874

Keywords: Maternal obesity, cervical ripening, balloon catheter

\section{Dear Editor,}

We are pleased to read the article "The effect of maternal obesity on the success of labor induction with a cervical ripening double-balloon catheter and on pain perception during catheter insertion" (1) by Kınay et al. (1) in Gülhane Medical Journal. In their study, the authors aimed to determine the impact of maternal body mass index (BMI) on the success of labor induction with a cervical ripening double-balloon catheter and to evaluate pain perception during catheter insertion. They also checked the cesarean delivery rates, normal delivery rates within 24 hours of labor induction, and visual analog scale pain scores during double-balloon catheter insertion between the women with a BMI at or above $30 \mathrm{~kg} /$ $\mathrm{m}^{2}$ and women with a BMI $<30 \mathrm{~kg} / \mathrm{m}^{2}$.

This study is important since it evaluates and provides data for the mechanical cervical ripening and pharmacological cervical ripening agents have some drawbacks due to side effects.

It will be nice if the authors have a chance to compare single balloon systems with double balloon systems in their future studies, since single balloon systems may be economically more convenient (2) and more readily available in limited source settings.

Also, it would have been nice to see whether the outcomes of the study would be different if BMI stratifications of normal (BMI: 18.5-24.9), overweight (BMI: 25-29.9), obese (BMI: 30-39.9) and very obese (BMI: over 40) had been used, rather than only non-obese and obese stratification. Of course, this would necessitate a higher number of participants.

As for the pain scores in the study, it has been mentioned by Torensma et al. (3) that some obese patient groups have lower pain thresholds, and some have higher pain thresholds, and Kınay et al.'s (1) study adds valuable data to the current literature.

\section{Ethics}

Peer-review: Externally peer-reviewed.

\section{Authorship Contributions}

Concept: E.N.S., K.E.K., Design: E.N.S., K.E.K., Data Collection or Processing: E.N.S., K.E.K., Analysis or Interpretation: E.N.S., K.E.K., Literature Search: E.N.S., K.E.K., Writing: E.N.S., K.E.K.

Conflict of Interest: No conflict of interest was declared by the authors.

Financial Disclosure: The authors declared that this study received no financial support. 


\section{References}

1. Kınay T, Dilbaz B, Özelçi R, Kahyaoğlu I, Maraloğlu Tekin Ö. The effect of maternal obesity on the success of labor induction with a cervical ripening double-balloon catheter and on pain perception during catheter insertion. Gulhane Med J. 2020;62:1-7.
2. Liu X, Wang Y, Zhang F et al. Double- versus single-balloon catheters for labour induction and cervical ripening: a metaanalysis. BMC Pregnancy Childbirth. 2019;19:358.

3. Torensma B, Thomassen I, van Velzen M, In 't Veld BA. Pain Experience and Perception in the Obese Subject Systematic Review (Revised Version). Obes Surg. 2016;26:631-639. 